\title{
Land Suitability Analysis for Identifying Industrial Zones in Duhok District, Kurdistan Region of Iraq
}

\author{
Zilan Adil ${ }^{1}$, Sarab Jabbar ${ }^{2}$, Ramadhan Haji Sulaiman ${ }^{3}$, Yaseen T. Mustafa ${ }^{4}$, Hazhir Karimi ${ }^{5, *}$ \\ ${ }^{I}$ Dept. of Environmental Science, Faculty of Science, University of Zakho, Kurdistan Region of Iraq, zilanbarwari23@gmail.com \\ ${ }^{2}$ Dept. of Environmental Science, Faculty of Science, University of Zakho, Kurdistan Region of Iraq, sarabbotani@gmail.com \\ ${ }^{3}$ Dept. of Petroleum, College of Engineering, University of Zakho, Kurdistan Region of Iraq, zaidky@hotmail.com \\ ${ }^{4}$ Dept. of Environmental Science, Faculty of Science, University of Zakho, Kurdistan Region of Iraq,yaseen.mustafa@uoz.edu.krd \\ *5ept. of Environmental Science, Faculty of Science, University of Zakho, Kurdistan Region of Iraq, hazhir.karimi@uoz.edu.krd \\ *corresponding author (hazhir.karimi@uoz.edu.krd)
}

\begin{abstract}
This process of industrial zones site selection requires to fulfill requirements and standards, simultaneously reducing environmental and public health costs and maximizing technical and economic benefits. A geographic information system was used in this study to evaluate land suitability to propose suitable sites for industrial zones in Duhok district, Kurdistan Region of Iraq. The defined parameters were classified into two groups, specifically, environmental and socioeconomic criteria. The information layers were prepared and were standardized into Boolean logic. The parameters maps were combined using the Boolean logic technique, and the suitability map was achieved on two classes including unsuitable and suitable. The results showed that only about $10 \%(104 \mathrm{Km} 2)$ of the study area was evaluated as suitable areas for industrial zones, which are mainly found in the north, northwest, and central parts of the study area. The results also illustrated that most of the industries within the study area have been located in inappropriate sites which have had a severe impact on the air quality of Duhok city. This paper would present a solution for industrial site selection in Duhok and it is helpful for regional planning of the country.
\end{abstract}

Keywords: Industrial zones, Site selection, GIS, Environmental considerations, Duhok.

Received: June 12m 2021 / Accepted: August 20, 2021 / Online: August 21, 2021

\section{INTRODUCTION}

Industrial site selection is the process of selecting potential sites in which attempt to satisfy a set of comprehensive requirements and could be helpful in regional planning plans $[1$, 2]. Traditionally, industrial site selection had been conducted based exclusively on economic and technical criteria; however, nowadays, a higher degree of consideration is desired [3, 4]. Considering a comprehensive set of criteria in site selection, not just only maximizes the economic benefits but also satisfies social and environmental requirements [5].

Most of the data used in industrial site selection are geographical, which means that this process is spatial decisionanalysis and decision making. The geographic information system (GIS) is a powerful tool for spatial analysis that provides the functionality to capture, store, query, analyze, display, and output geographic information [6]. The capability of GIS makes it beneficial for environmental management and planning and in combination with other geoinformatics techniques have widely been used for various environmental studies such as land use/land cover change detection $[7,8,9,10,11]$, environmental quality assessment $[12,13,14,15,16]$, and site selection and land suitability analysis $[17,18,19]$.

Besides, the application of GIS combined with multicriteria decision analysis has been used for industrial site selection. The previous studies have considered a comprehensive set of parameters mainly including environmental, social, economic, and technical criteria. For instance, in a study by Rikalovic et al., a GIS-based multi-criteria analysis for industrial site selection was used by considering technical, social, environmental, and economic factors [1]. Salari et al. used GIS and the analytical

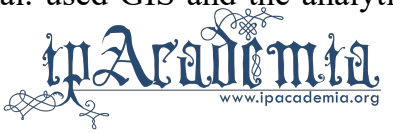


hierarchy process for determining the best sites for industrial zones [20]. Karimi et al. applied GIS and multicriteria decision analysis for site selection and comprised two aggregation methods named weighted linear combination and Fuzzy logic [21].

The Duhok Governorate is a strategic location in the Kurdistan Region of Iraqi as a joint point among the three parts of Kurdistan (Syria, Turkey, and Iraq), which has made it a growing commercial and industrial location and important center for the tourism industry. In the last years, the Kurdistan Region government has attempted to develop the industrial sector of the Duhok Governorate. Although the government recognizes the urgent need to move toward sustainable development, most industrial developments have ignored environmental consideration that is a required aspect of sustainable development. Industries have harmful impacts on the environment and ecosystem and industrial planning should be seriously planned much more important than other developments.

The air quality in Duhok City has decreased in the last years because of the industries established near the city and residential areas. Also, Duhok and other cities are dependent on fossil fuels to generate power; however, the generated power does not meet demand. To meet this gap, private diesel power generation has grown significantly that consumes a high volume of fuel. The further inappropriate development could gradually worse the current situation therefore new industrial sites should be planned carefully. This study aims at determining the suitable sites for industrial zones based on the effective parameters and using geoinformatics techniques. The result of this study would help the decision-makers and planners to establish new optimal sites and to improve the current state of the industries in the study area.

\section{CASE STUDY AND METHODS}

\section{A. Case Study}

The Duhok Governorate consists of seven districts, including Duhok, Semel, Zakho, Amedy, Sheikhan, Akre, and Bardarsh. Duhok has a strategic location since it lies at the joint point of Iraq, Turkey, and Syria. The study area in this study is the Duhok district approximately located between latitudes $37^{\circ} 6^{\prime} 17^{\prime \prime} .89$ and $36^{\circ} 48^{\prime} 26^{\prime \prime} .41$ and longitudes $42^{\circ} 47^{\prime} 49^{\prime \prime} .86$ and $43^{\circ} 18^{\prime} 44^{\prime \prime} .13$. The elevation of ranges between 430 and $1520 \mathrm{~m}$ above sea level, covering an area of $1014.31 \mathrm{~km}^{2}$ (Fig. 1). Its population has multiplied in the last decades as the rural population moved to the city. The climate is rainy, cold in winter, and sunny, dry in summer where the area shows various land covers.

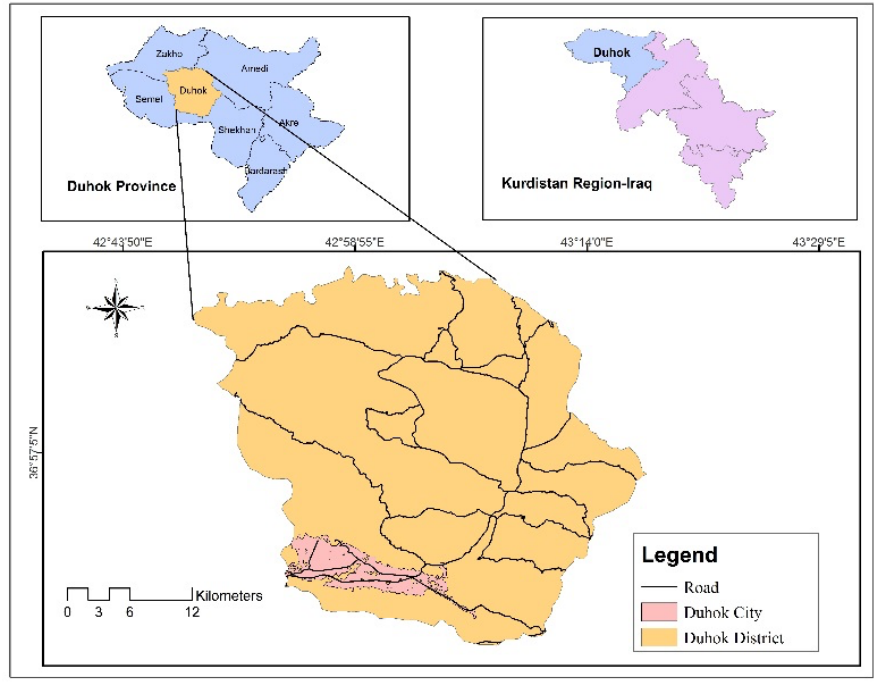

Fig. 1. Location of the study area, Duhok district.

\section{B. Data Collection and Preparation of layers}

For identifying suitable industrial zones, effective factors should be identified first. In this study, the factors were selected from previous similar research $[1,2,3,20,21,22,23,24,25$, 26, 27], and national and international regulations. A comprehensive set of factors were identified and then the factors were carefully screened to select the final factors based on data availability. We classified the factors into two types: environmental and socio-economic criteria. The environmental criteria were distance to the river, distance to lake and dams, land use, and distance to natural/protected areas. The socioeconomic factors included distance to roads, distance to residential areas, slope, distance to the village, and cities' distance. The selected criteria are shown in Fig. 2.

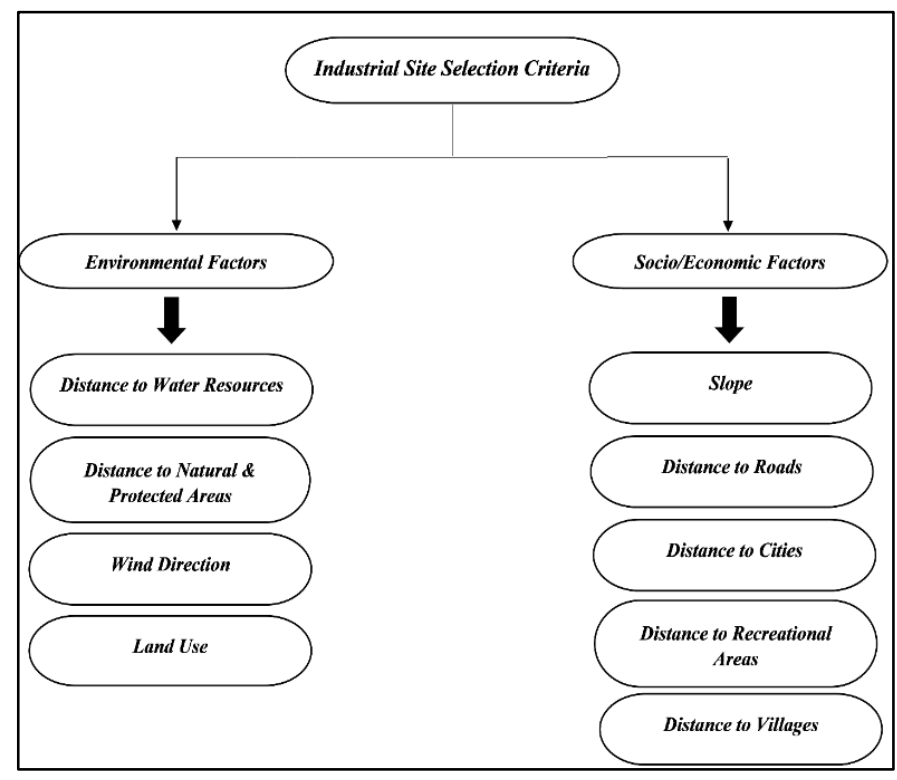

Fig. 2. Criteria and sub-criteria used in this study. 
The defined data and information layers were acquired from several sources including field surveys, satellite images, google earth, paper maps, and available information from related organizations. The information layers were then prepared using ArcGIS 10.3. Since the factors have different units (e.g. slope in percent and distances in meters or kilometers), it is necessary to convert the maps to the same scale. Boolean Logic was used to standardize the maps. Based on this approach, the maps were classified into a value of 0 (unsuitable) and 1 (suitable). Table 1 shows the classes of the criteria and the suitable and unsuitable ranges. The flowchart of the methodology is also shown in Fig. 3 . In the following, the process of preparing factors is described in detail.

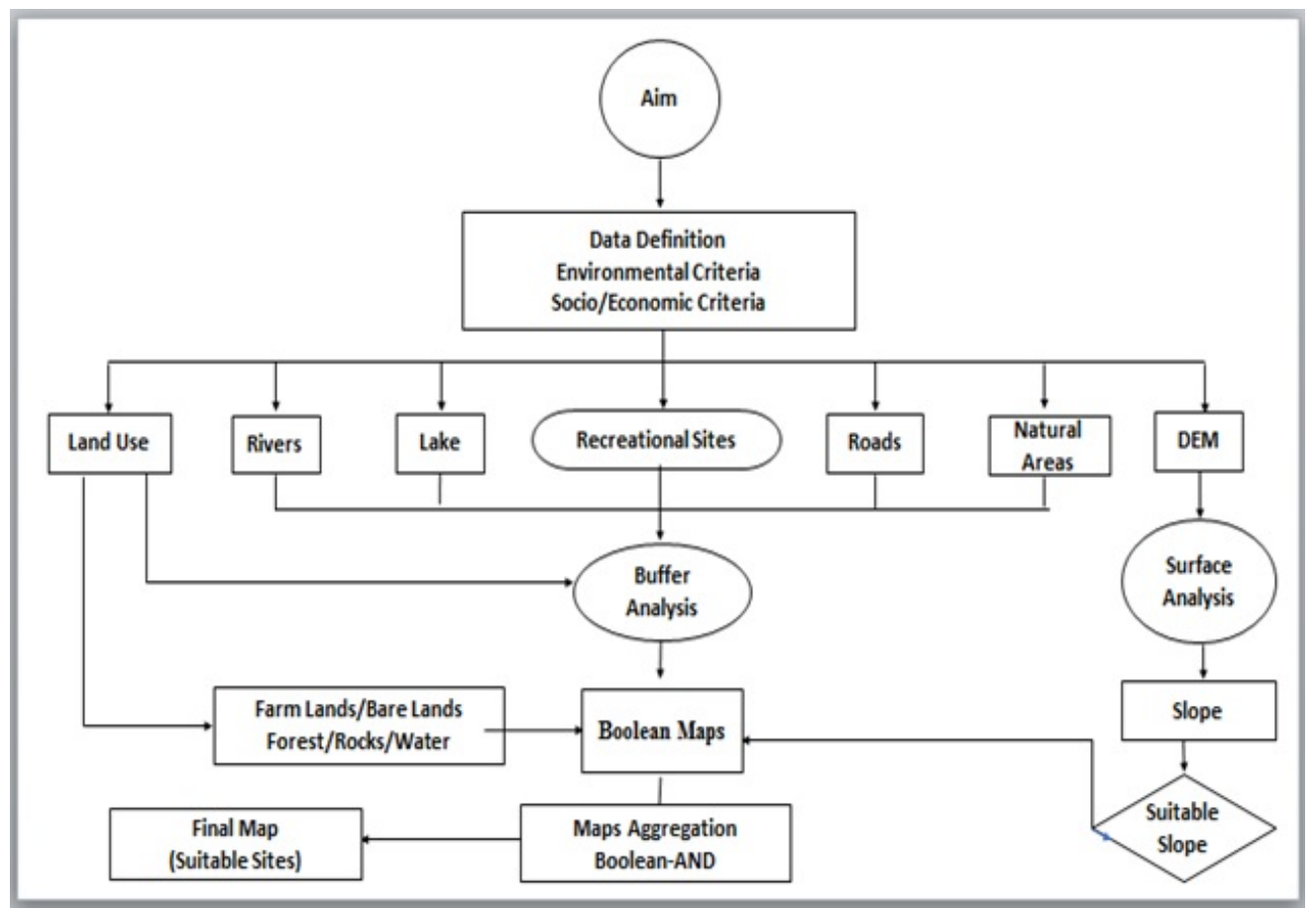

Fig. 1. Flowchart of the methodology.

Table 1. Range of suitable and suitable classes of the factors

\begin{tabular}{ccc}
\hline Factor & Suitable (0) & Unsuitable (1) \\
\hline $\begin{array}{c}\text { Distance to river (m) } \\
\text { Distance to lake (m) }\end{array}$ & $>800$ & $<800$ \\
$\begin{array}{c}\text { Distance to protected and } \\
\text { natural areas(m) }\end{array}$ & $>1000$ & $<2000$ \\
Distance to cities (m) & $>3000$ & $<1000$ \\
Distance to villages (m) & $>1500$ & $<3000$ \\
Distance recreational areas & $>1000$ & $<1500$ \\
(m) & $>250$ & $<250$ \\
Distance to roads (m) & $<3000$ & $>3000$ \\
Slope (\%) & $<40$ & $>40$ \\
Land use type & $\begin{array}{c}\text { Bare lands, } \\
\text { farmlands, } \\
\text { range lands }\end{array}$ & $\begin{array}{c}\text { Forests, water, } \\
\text { residential areas, } \\
\text { rocks }\end{array}$ \\
\hline
\end{tabular}

\section{Boolean Maps}

\section{- Environmental Factors}

Distance to the water resources, distance to protected areas, wind direction, and land use/cover types were selected as the environmental factors. The factor maps were classified into two classes of unsuitable and suitable (Table 1). For instance, a distance within $800 \mathrm{~m}$ of the rivers and $2000 \mathrm{~m}$ of the dam (lake) were considered unsuitable areas. The location of protected areas and natural habitats should be strictly considered in industrial establishments. There is no preserved area within the case study, only the Zawita forest has the preservation value. Therefore, a buffer of $2000 \mathrm{~m}$ around Zawita forest was defined as an unsuitable area. From the land-use layer, residential areas, forests, croplands, and water bodies were considered unsuitable, whereas soil (bare land) was defined as suitable. The prepared Boolean maps are shown in Fig. 4.

- Socio-economic Factors

Distances to residential areas (villages and cities), distances to recreational areas, distances to roads, and slopes were selected as social and economic factors. Pollutants and contaminations from industries might annoy residential areas and therefore it is 
essential to consider minimum border a distance between industries location and settlements. We defined two buffers in this research - one for cities and another for rural areas. By using the buffer analysis tool of ArcGIS, $3000 \mathrm{~m}$ buffer for Duhok city and $1500 \mathrm{~m}$ for villages were defined. Also, a minimum distance of $1000 \mathrm{~m}$ was considered as an unsuitable area from recreational areas.

Distance from the roads is an important economic factor in industrial site selection. The location of industries should not be so far from roads to decrease transportation costs. Therefore, distances more than $3000 \mathrm{~m}$ were considered unsuitable areas. Another important economic factor is the slope that was derived from the Digital Elevation Model (DEM) with a spatial resolution of $30 \mathrm{~m}$. The slope layer was classified into two classes: $0-40 \%$ and more than $40 \%$. Areas within the slope of 0 $40 \%$ were considered a suitable class. The Boolean maps of these factors are shown in Fig. 4.

\section{Aggregation Layers}

After preparing all Boolean maps, the maps were then overlaid for finding the suitable areas for the industrial zones. As mentioned, all maps were classified into two classes: suitable and unsuitable. Suitable class is those regions that were defined as appropriate areas for industrial zones while unsuitable are prohibited areas. Before maps aggregation, all maps were converted into the same scale and same coordinate system. The maps were finally overlaid using the Boolean Logic-AND operator.

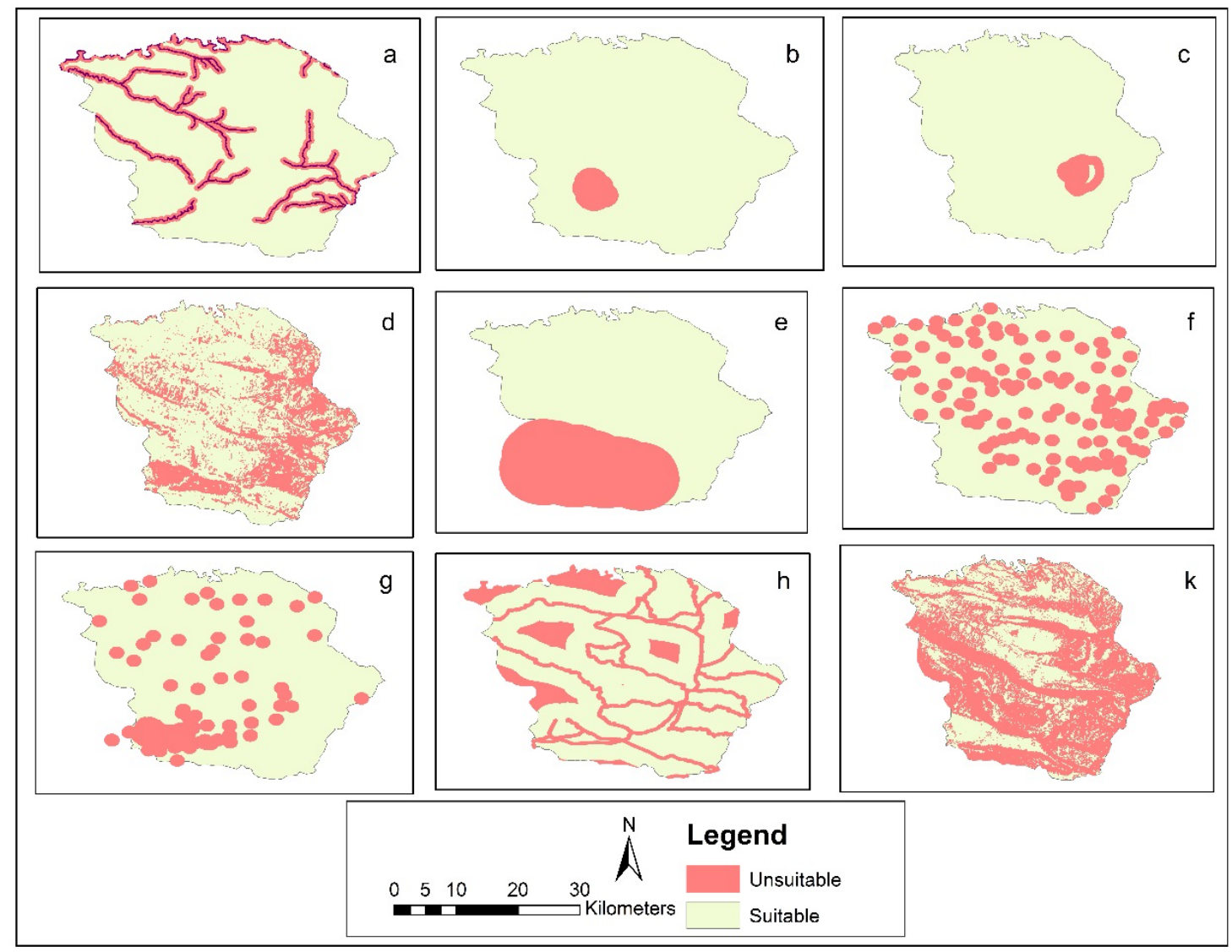

Fig. 4. Boolean factors maps: a (distance to rivers), b (distance to lakes), c (distance to protected areas), d (land use), e (distance to cities), $\mathrm{f}$ (distance to villages), $\mathrm{g}$ (distance to recreational sites), $\mathrm{h}$ (distance to roads), $\mathrm{k}$ (slope)

\section{RESULTS AND DISCUSSION}

In this study, land capability evaluation for industrial zones was conducted using a GIS and by considering various factors. Nine factors were considered, and the maps of the criteria were prepared. The maps were classified and aggregated using Boolean logic. Fig. 5 depicts the land suitability for the industrial zone establishment in the study areas. The results show that just about $10 \%(104 \mathrm{Km} 2)$ of the study area has a suitable capability for industrial zone establishment, whereas $90 \%(910 \mathrm{Km} 2)$ of the Duhok district is evaluated as an unsuitable class. Suitable areas are mostly found in the north, northwest, and central parts of the study area; in contrast, the west, east, and southern parts have no suitability for industrial zones. The unsuitable areas are mostly covered by dense forests, recreational areas, water bodies, and villages. 


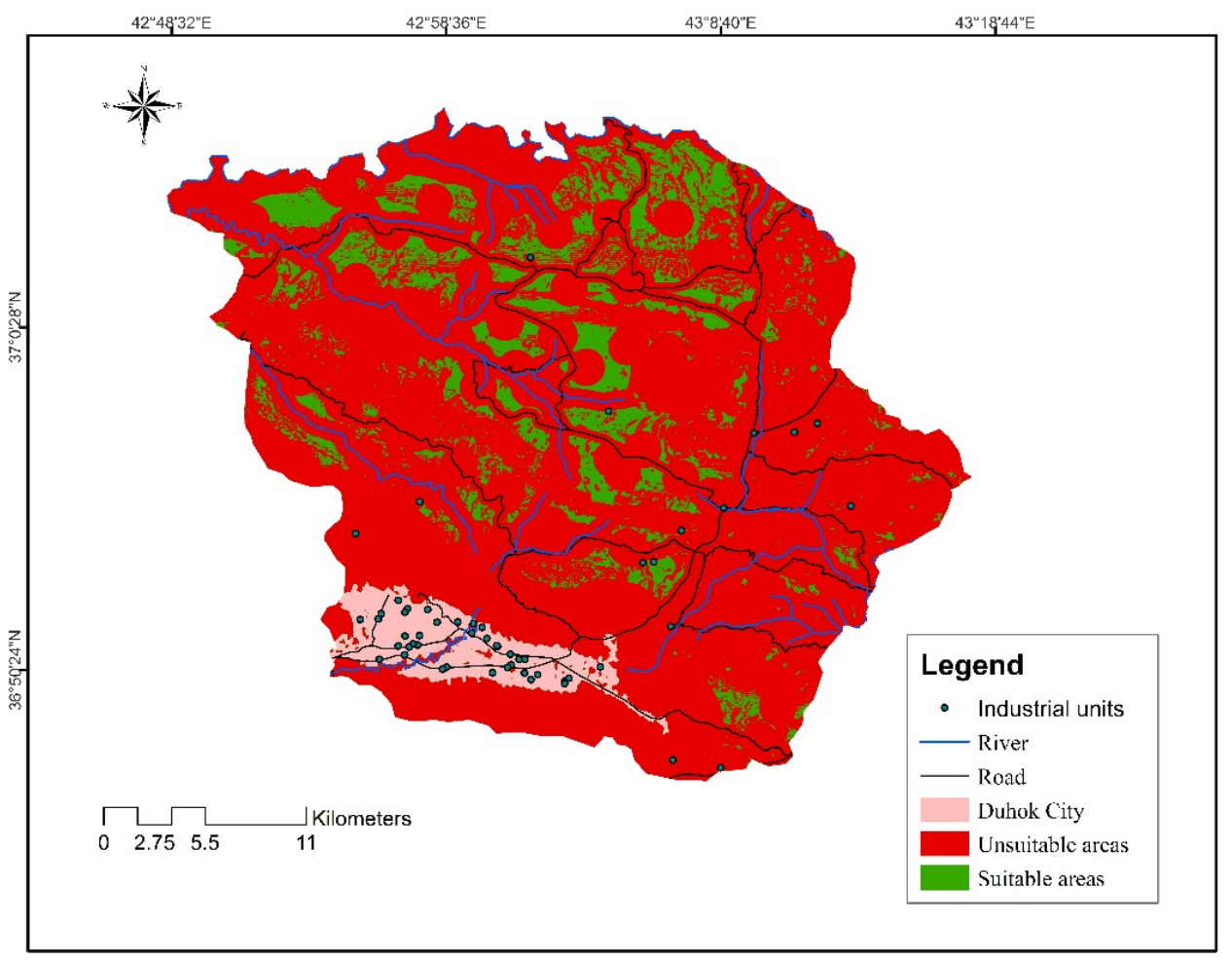

Fig. 5. Map of the land capability to industrial zones development in Duhok District.

In general, it has been suggested to select the minimum area of 100 hectares $(1 \mathrm{Km} 2)$ for industrial zone establishment. Considering the minimum area, most of the proposed sites are suitable for this aim. Nevertheless, access to power lines and marketing need to be considered. Through our visiting and field checking, we found that many industrial units have been constructed within the Duhok district and especially near Duhok city, meaning that the process of site selection has not been considered when developing the industry sector in this district. As can be seen from Fig. 5, most of the industries within the study area have been located in inappropriate sites which have had a severe impact on the air quality of Duhok city.

Selecting criteria and factors is an essential step that affects the final suitability analysis. While most of the development in Duhok governorate has been invested by considering limited factors and mostly focused on the economic aspects. We put more focus on environmental consideration and social aspects. The maximum consideration was determined for the environmental criteria such as distance to water bodies, distance to natural areas such as Zawita forest region, and distance to residential areas for avoiding possible pollutions and contaminations.

Using Fuzzy Logic AND-operator, the selected suitable areas were very small in terms of area compared to the other aggregation methods. This is partially due to considering the minimum degrees of relevance within each factor function and ideal condition in the Boolean Logic-AND operator method. In terms of relative risk, AND operation is very conservative to make the possible risks minimum. Therefore, AND operator is an ideal method since considering the highest sensitivity analysis, meaning that this method is appropriate for environmental management. It is suggested to consider other methods such as fuzzy logic, and weighted linear combination (WLC) and compare the result with our findings.

The obtained results in this research in the ability of AND operator the site selection process agree with previous studies. Karimi et al. used and compared aggregation methods for power plant site selection. They stated that fuzzy logic produces more relevant results and more flexibility while there is a higher level of sensitivity with Boolean Logic- AND [21]. Minish et al. (2018) assessed potential locations for industrial development by using GIS-based MCDA. Seven constraints and 23 factors were evaluated. They stated that the integrated GIS-MCA can serve as a policy and planning tool for locating industrial zones while retaining environmental protection [27].

\section{CONCLUSION}

Industrial site selection is a spatial task that involves a broad set of feasible parameters and alternatives. In this study, based on the various criteria and sub-criteria, the Dohuk district was evaluated for finding the best sites for industrial zones. The overall results indicated that the study area has a limited capability for the industrial zone setting due to the forests, the rivers, and also the high density of the villages. Moreover, considering various criteria and alternatives, standardization of criterion scores, and making suitability maps for each criterion 
gives this opportunity to perceive each criterion separately and together through the final suitability map.

\section{ACKNOWLEDGMENT}

We would like to thank the University of Zakho to support this project. We also express our sincere thanks to the Local government organizations and divisions for their cooperation during data collection.

\section{REFERENCES}

[1] A. Rikalovic, I. Cosic, \& D. Lazarevic. GIS Based Multi-Criteria Analysis for Industrial Site Selection. Procedia Engineer, 69, 10541063, 2014.

[2] F. Edrahim, A. Mehdi, F. Habib, Md. Ali. Industrial state site selection using MCDM method and GIS in Germi, Ardabil, IRAN. J Ind Intell Inf, 3(4), 324-329, 2015.

[3] EK. Ramcharan, PK. Dey. The role of environmental factors in industrial site selection activities: a case of limestone quarry expansion in Barbados, West Indies. Impact Assess Proj Apprais, 23(2), 147-154, 2005. doi:10.3152/147154605781765670

[4] H. Ramin, P. Hanafizadeh, M.A. Akhavan Behabadi. Thermal, Economical and Environmental Optimization of Insulation Thickness in Residential Building's Wall. Modares Mech Engineer, 16, 13, 252-255. 2017.

[5] H. Karimi, B. M. A. Herki, S. Q. Gardi, S. Galali, H. Hossini, K. Mirzaei \& M. Pirsaheb. Site selection and environmental risks assessment of medical solid waste landfill for the City of Kermanshah-Iran, International Int $\mathrm{J}$ Environ Heal R, 2020. 10.1080/09603123.2020.1742876

[6] J. Malczewski. GIS-based multicriteria decision analysis: a survey of the literature, Int J Geogr Inf Sci, 20, 7, 703-726, 2006. $10.1080 / 13658810600661508$.

[7] H. Karimi, J. Jafarnezhad, J. Khaledi \& P. Ahmadi. Monitoring and prediction of land use/land cover changes using CA-Markov model: a case study of Ravansar County in Iran. Arab J Geosci. 11 (592). 2018. https://doi.org/10.1007/s12517-018-3940-5

[8] A. Kourosh Niya, J. Huang, A. Kazemzadeh-Zow, H. Karimi, Naimi. Comparison of three hybrid models to simulate land use changes: a case study in Qeshm Island, Iran. Environ Monit Assess 192, 302. 2020. https://doi.org/10.1007/s10661-020-08274-6

[9] F.Effati, H. Karimi \& A. Yavari. Investigating effects of land use and land cover patterns on land surface temperature using landscape metrics in the city of Tehran, Iran. Arab J Geosci. 14, 1240. 2020. https://doi.org/10.1007/s12517-021-07433-4

[10] Y. T. Mustafa. Multi-temporal Satellite Data for Land Use/Cover (LULC) Change Detection in Zakho, Kurdistan Region-Iraq. In: Al-Quraishi A., Negm A. (eds) Environmental Remote Sensing and GIS in Iraq. Springer Water. Springer, Cham. 2020. https://doi.org/10.1007/978-3-030-21344-2_7

[11] Y. T. Mustafa. Spatiotemporal Analysis of Vegetation Cover in Kurdistan Region-Iraq using MODIS Image Data, JASTT. 1 (1), 1-07. 2020.

[12] S. Galalizadeh, H. Karimi, B. Malekmohammadi, A. Sadeghi, S. Shirzadi. Environmental risk assessment and mapping of oil installations to Chamshir Dam water basin using GIS and HAZOP method. International Journal of Risk Assessment and Management, 23(3/4), 207. 2020. http://dx.doi.org/10.1504/ijram.2020.114358

[13] Muhammed, H. Karimi, B. Gharab, S. Neamat, and K. Mirzaei. Assessment of the Quality of the Environment in Duhok Province, Kurdistan Region of Iraq. JoCEF, 1 (1), 20-24, 2020.

[14] S. Neamat and H. Karimi. A systematic review of GIS-based landslide Hazard Mapping on Determinant Factors from International Databases," 2020 International Conference on Advanced Science and Engineering (ICOASE), 180-183. 2020. 10.1109/ICOASE51841.2020.9436611

[15] N. Haregeweyn, A. Tsunekawa, J. Poesen, M. Tsubo, D. T. Meshesha, A. A. Fenta, J. Nyssen, E. Adgo. Comprehensive assessment of soil erosion risk for better land use planning in river basins: A case study of the Upper Blue Nile River. Sce Total Environ 574, 95-108, 2017.

[16] H. Karimi, A. Soffianian, N. Mirghaffari,. Determining Air Pollution Potential Using Geographic Information Systems and Multi-criteria Evaluation: A Case Study in Isfahan Province in Iran. Environ. Process, 3, 229-246. 2016. https://doi.org/10.1007/s40710-016-0136-4

[17] H. Karimi, M. Bengin, A. Herki, S. Gharibi, S.Hamiditehrani, A. Kakhani. Identifying Public Parking Sites Using Itegrating GIS And Ordered Weighted Averaging Approach in Sanadai City, Iran. JCR; 7(4), 506-513. 2020.

[18] V. Nørstebø, S. O. Krøgli, M. Debella-Gilo. Identifying Suitable Bioeconomic Cluster Sites-Combining GIS-MCDA and Operational Research Methods. Environ Model Assess 25, 689-703. 2020. https://doi.org/10.1007/s10666-020-09694-x

[19] H. Karimi, S. Amiri, Huang, A. Karimi. Integrating GIS and multicriteria decision analysis for landfill site selection, case study: Javanrood County in Iran. Int. J. Environ. Sci. Technol. 16, 73057318, 2019. https://doi.org/10.1007/s13762-018-2151-7

[20] M. Salari, S. M. Shariat, R. Rahimi, \& S. Dashti. Land capability evaluation for identifying industrial zones: combination multicriteria decision-making method with geographic information system. Int. J. Environ. Sci. Technol, 16, 5501-5512, 2019. https://doi.org/10.1007/s13762-018-1925-2

[21] H. Karimi, A. Soffianian, S. Seifi, S. Pourmanafi, \& H. Ramin, Evaluating optimal sites for combined-cycle power plants using GIS: comparison of two aggregation methods in Iran. Int J Sustain Energy, 39, $101-112,2020$.

[22] I. Rikalovic, R. Cosic, D. Labati and V. Piuri. Intelligent Decision Support System for Industrial Site Classification: A GIS-Based Hierarchical Neuro-Fuzzy Approach. IEEE Syst J, 12, 3, 2970-2981, 2017. doi: 10.1109/JSYST.2017.2697043.

[23] H. Ramin, H. Karimi. Optimum envelope design toward zero energy buildings in Iran. E3S Web Conf, 172 16004, 2020. DOI: https://doi.org/10.1051/e3sconf/202017216004

[24] M. Raisi, A. Soffianian, Industrial site selection by combining geographic information system and multi criteria decision analysis, WULFENIA. 20, 116-129, 2013.

[25] S. Siefi, H. Karimi, A. Soffianian, \& S. Pourmanafi, GIS-Based Multi Criteria Evaluation for Thermal Power Plant Site Selection in Kahnuj County, SE Iran. Civ Eng Infrast J, 50, 179-189, 2017.

[26] H. Ramin, P. Hanafizadeh, T. Ehterami, M. A. AkhavanBehabadi. Life cycle-based multi-objective optimization of wall structures in climate of Tehran. Adv. Build. Energy Res, 13, 1, 18-31, 2019. 10.1080/17512549.2017.1344137

[27] N. Muhsin, T. Ahamed, \& R. Noguchi, GIS-based multi-criteria analysis modeling used to locate suitable sites for industries in suburban areas in Bangladesh to ensure the sustainability of agricultural lands,2018, Asia-Pac J Reg Sci 2, 35-64 https://doi.org/10.1007/s41685-017-0046-0 